\title{
Analysis of Flexural \\ NSRC-HSRC Composite Members Cracking Behaviour and Concrete Properties
}

\section{Tadas Zingaila*, Mindaugas Augonis}

Kaunas University of Technology, Faculty of Civil Engineering and Architecture

Studentu st. 48, LT-51367 Kaunas, Lithuania

*Corresponding author: tadaszingaila@gmail.com

Г

Crossef http://dx.doi.org/10.5755/j01.sace.8.3.7144

The application of high strength concrete to reinforced concrete structures is very popular nowadays. This paper presents two main topics. In the first part of this paper, it is presented elasto-plastic properties of normal and high strength compressive concrete. It is known that actual behaviour of concrete is nonlinear. Design standard EN 1992-1-1 provides nonlinear stress-strain relation of compressive concrete for structural analysis. Expression to calculate this relation is given in standard. In this article, there are suggested coefficients which evaluate elasto-plastic behaviour of normal and high strength compressive concrete. Good correlation can be observed between stress-strain relation of compressive concrete given in standard EC2 and calculated relation using suggested elasto-plastic coefficients. In the second part of the paper, it is presented an overview of cracking moment calculations of reinforced concrete composite flexural members made from normal and high strength concrete and normal cross-section beams. These calculations were performed using existing design standard, technical construction regulation, structural building code (EN 1992-1-1, STR 2.05.05:2005, ACl 318) and layer method. New approximate values of elasto-plastic coefficients were suggested for tension concrete.

KEYWORDS: cracking moment, high strength concrete, stress-strain curve, elasto-plastic behaviour, composite beams.

The applicability of concrete in structures is very popular due to various reasons: strength, durability, versatility, fire-resistance, etc. Concrete is also known as ecological building material. Mechanical properties of concrete are continuously studied. It is well known that the real behaviour of the concrete is nonlinear. However, the bigger part of the design standards provide cracking moment calculation methods, where the assumptions are made that the behaviour of the concrete is elastic (ACl 318; EC2; Mosley, Bungey and Hulse 2007; Wight and MacGregor 2008). When the calculations of cracking moment are performed, it is normal that the compression zone of the flexural member behaves elastically, but the real behaviour of the tension zone is nonlinear. The influence of tension zone nonlinearity should be taken into account when the calculations are performed. However, it can be observed that there are too little publications, books, or other sources about the stress-strain relation of tensile concrete. It is difficult to obtain direct tensile stress-strain curve, therefore limited and conflicting data of tensile concrete stress-strain relation are available (Kumar et al.; Shi et al., 2008). Influence of tensile concrete elasto-plastic behaviour is especially important in serviceability calculations (cracking moment, deflection, curvature, etc.).

\section{Introduction}

Analysis of Flexural NSRC-HSRC

Composite Members Cracking Behaviour and Concrete Properties

Received 2014/05/22

Accepted after revision 2014/07/05

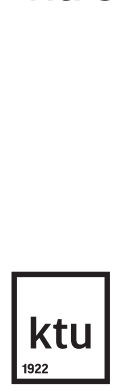

Journal of Sustainable Architecture and Civil Engineering Vol. 3 / No. 8 / 2014 pp. 83-91

DOI 10.5755/j01.sace.8.3.7144 (C) Kaunas University of Technology 
According to STR and EC2, it is assumed that elastic zone of compressive concrete is approximately equal to $0.4 f_{\mathrm{cm}}$. However, it is observed that for high strength concrete the zone of elastic stress-strain relation is higher than for normal strength concrete. It was determined by Iravani et al. (1994) that depending on the class of high strength concrete, the value of this coefficient can reach 0.85 or even higher.

Great attention is given to the applicability of high strength concrete to reinforced concrete structures. In order to optimize or improve behaviour of reinforced concrete flexural members, series of analysis are performed. Partial use of high strength concrete can increase stiffness of the reinforced concrete composite beams, ultimate capacity, initial cracking load and other parameters, when comparing with the beams which are made from normal strength concrete. It is observed that partial use of HSC (high strength concrete) can reduce crack width. Composite beams can be also named as hybrid beams. Various configurations of composite beams layers are possible. Strengthening by high strength concrete can be provided in compression zone, tension zone or in compression and tension zones together. Casting operation of composite NSRC-HSRC (two layers of normal and high strength concrete) beams can be performed in two cases. In the first case, both layers can be cast while the concrete is in fresh condition. This should insure full bond between different layers of the concrete. Also, it is observed that transverse reinforcement can increase bond between the layers. In the other case, the second layer of new concrete can be cast when the first layer of concrete reaches its design strength (after 28 days or even later). This case can be applied for the analysis of the structural members which have to be rehabilitated or repaired. However, long time between casting phases could require additional tools to insure full bond between two layers of the concrete. Application of steel fibre reinforced concrete is common in composite cross-section beams, but in this study only by steel bars reinforced concrete flexural members are analysed (Kheder et al., 2010; Lapko et al., 2005; Sadowska-Buraczewska et al., 2007).

There is no united design standard which provides the calculation method for such type of the flexural members. It should be noted that it is necessary to take into account nonlinear behaviour of tension and compression concrete. Therefore, this paper is intended for the analysis of the flexural NSRC-HSRC composite members cracking behaviour and concrete properties.

Estimation coefficient $\lambda_{c, \lim }$ according to EC2 stress-strain relation
Design standard EC2 provides stress-strain relation of normal and high strength compressive concrete for nonlinear structural analysis. It includes concrete classes from C12/15 to C90/105.

The relation between $\sigma_{c}$ and $\varepsilon_{c}$ can be calculated according to the expression:

$$
\frac{\sigma_{c}}{f_{c m}}=\frac{k \eta-\eta^{2}}{1+(k-2) \eta}
$$

where: $\eta=\varepsilon_{c} / \varepsilon_{c 1} ; \varepsilon_{c}$ - compressive strain in the concrete; $\varepsilon_{c 1}$ - strain at peak stress; $k=1.05 \cdot E_{c m} \cdot \varepsilon_{c 1} \mid / f_{c m} ; E_{c m}$ - secant modulus of elasticity of the concrete; $f_{c m}$ - mean value of concrete cylinder compressive strength.

This expression (1) is valid for $0<\left|\varepsilon_{c}\right|<\left|\varepsilon_{c u l}\right|$. Here $\varepsilon_{c u 1}$ is the nominal ultimate strain.

When the strain in the concrete reaches the limit elastic strain of compressive concrete, the behaviour of the concrete changes from elastic to elasto-plastic, and here secant modulus of elasticity of concrete has to be recalculated to the deformation modulus of concrete. This modulus can be calculated according to the expression:

$$
E_{c}^{*}=\lambda_{c} E_{c m}
$$

where: $\lambda_{c}$ - coefficient which evaluates elasto-plastic deformations of compressive concrete;

The expression (3), given in Augonis et al. (2013) publication can be used to determine coefficient which evaluates elasto-plastic behaviour of compressive concrete. However, the limit value of this coefficient depends on the concrete class. 


$$
\lambda_{c}=1-k_{c} \frac{\varepsilon_{c, i}-\varepsilon_{c, e l}}{\varepsilon_{c, l i m}-\varepsilon_{c, e l}} ;
$$

concrete; $\varepsilon_{c, \text { lim }}$ - the limit strain of compressive concrete at the peak stress.

The limit elastic strain of the compressive concrete can be calculated according to the expression:

$$
\varepsilon_{c, e l}=\frac{k_{e l, c} \cdot f_{c m}}{E_{c m}}
$$

The limit strain of compressive concrete at the peak stress can be calculated according to the expression:

$$
\varepsilon_{c, l i m}=\frac{f_{c m}}{\lambda_{c, l i m} E_{c m}} ;
$$

EC2 provides stress-strain relation until the nominal ultimate strain $\varepsilon_{\text {cul }}$. In this research cracking moment calculations are performed. The assumption is made that $\lambda_{c, \text { lim }}$ values are applied to obtain the limit strain of tensile concrete, due to this reason only the first part of stressstrain relation is analysed (until the limit strain of compressive concrete at the peak stress $-\varepsilon_{c l}$ ). From Fig. 1. can be observed that stress-strain relation calculated according to expression (1), which is given in EC2, has a good correlation with suggested stress-strain relation which is calculated using $k_{e l, c}$ and $\lambda_{c, \text { lim }}$ coefficients. It also can be seen that with the increase of the concrete class, the linear part of stress-strain relation also increases.

In order to calculate the limit elastic strain of the compressive concrete $\varepsilon_{c, e l^{\prime}}$ which approximately corresponds the where: $k_{e l, c}$ - coefficient which evaluates the limit of elastic strain of compressive concrete; cient which evaluates elasto-plastic deformations of compressive concrete; $\varepsilon_{c, i}$ - compressive strain in the concrete; $\varepsilon_{c, e l}$ - limit elastic strain of compressive shape of EC2 stress-strain curve, coefficient $k_{e l, c}$ is suggested for different concrete classes. The values of this coeficient using mentioned method vary from 0.01 to 0.4 for concrete classes from $\mathrm{C} 20 / 25$ to $\mathrm{C} 45 / 55$, and respectively from 0.5 to 0.65 for the concrete classes from $\mathrm{C50/60}$ to $\mathrm{C} 90 / 105$. It is a tendency that for ultra-high strength concrete the value of this coefficient could be even higher. However, in the cracking moment calculations not less than 0.4 is assumed to evaluate the elastic zone of concrete.

To obtain accurate values of $k_{e l, c}$ coefficients, more experimental analysis is necessary. Summary of the specific values of approximate coefficients are given in Table 1 and Table 2.

To determine the limit strain of the compressive concrete at the peak stress, $\lambda_{c, \text { lim }}$ coefficient is

Fig. 1

Comparison of stressstrain relation of compressive concrete calculated according to EN 1992-1-1 and stress-strain relation $\left.{ }^{*}\right)$ calculated using coefficients $\mathrm{k}_{\mathrm{el}, \mathrm{c}}$ and $\lambda_{\mathrm{c}}$. 
Fig. 2

Variation of coefficient $\lambda$ for different concrete classes

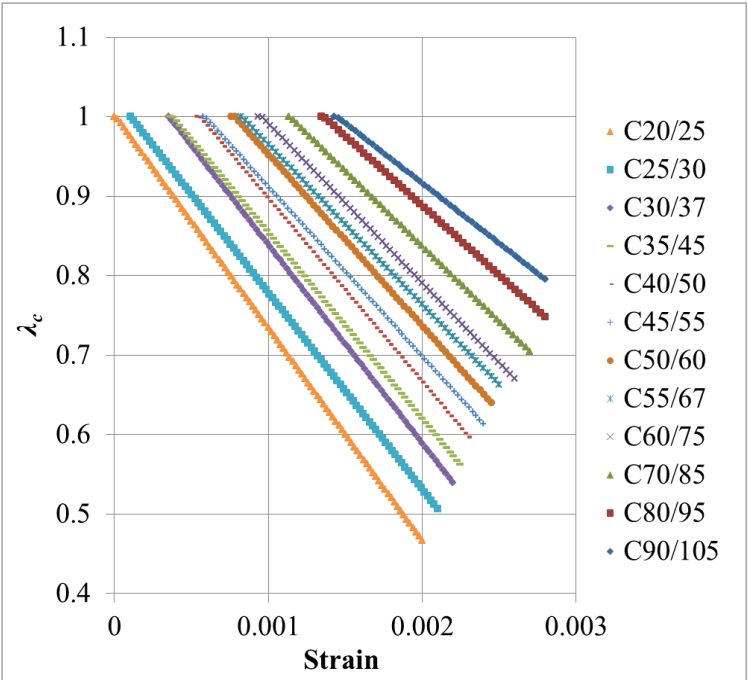

used. The approximate values of this coefficient vary from 0.467 to 0.613 for concrete classes from $\mathrm{C} 20 / 25$ to $\mathrm{C} 45 / 55$, and respectively from 0.640 to 0.795 for the concrete classes from C50/60 to C90/105. The same tencency as for coeffient $k_{\text {el,c }}$ remains that for ultra-high strength concrete the value of this coefficient could be even higher. Summary of the specific values of approximate coefficients are given in Table 1 and Table 2.

In Fig. 2. it is presented the variation of $\lambda_{c}$ coefficient, depending on the class of the concrete. The similar values of these coefficients are calculated by Židonis

(2013). It can be observed that elasto-plastic deformations for high strength concrete occurs at much higher strain level than for normal strength concrete. When concrete behaviour is elastic, it is assumed that the deformation modulus of the concrete is equal to secant modulus of elasticity, and then the value of coefficient $\lambda_{c}$ is equal to 1 .

Table 1 Summary of results for concrete classes from $\mathrm{C} 20 / 25$ to $\mathrm{C} 45 / 55$

Table 2 Summary of results for concrete classes from $\mathrm{C} 50 / 60$ to $\mathrm{C} 90 / 105$

\begin{tabular}{c|c|c|c|c|c|c}
\hline Characteristics & $\mathrm{C} 20 / 25$ & $\mathrm{C} 25 / 30$ & $\mathrm{c} 30 / 37$ & $\mathrm{C} 35 / 45$ & $\mathrm{C40/50}$ & $\mathrm{C45} / 55$ \\
\hline$f_{c m}(\mathrm{MPa})$ & 28 & 33 & 38 & 43 & 48 & 53 \\
\hline$E_{c m}(\mathrm{MPa})$ & 30000 & 31000 & 33000 & 34000 & 35000 & 36000 \\
\hline$\varepsilon_{c 1}=\varepsilon_{c, \text { lim }}$ & 0.002 & 0.0021 & 0.0022 & 0.00225 & 0.0023 & 0.0024 \\
\hline$\varepsilon_{c u 1}$ & 0.0035 & 0.0035 & 0.0035 & 0.0035 & 0.0035 & 0.0035 \\
\hline$k_{\text {el, }}$ & 0.01 & 0.10 & 0.30 & 0.30 & 0.40 & 0.40 \\
\hline$\lambda_{c, \text { lim }}$ & 0.467 & 0.507 & 0.523 & 0.562 & 0.596 & 0.613 \\
\hline$k_{c}=1-\lambda_{c, \text { lim }}$ & 0.533 & 0.493 & 0.477 & 0.438 & 0.404 & 0.387 \\
\hline
\end{tabular}

\begin{tabular}{c|c|c|c|c|c|c}
\hline Characteristics & C50/60 & C55/67 & C60/75 & C70/85 & C80/95 & C90/105 \\
\hline$f_{c m}(\mathrm{MPa})$ & 58 & 63 & 68 & 78 & 88 & 98 \\
\hline$E_{c m}(\mathrm{MPa})$ & 37000 & 38000 & 39000 & 41000 & 42000 & 44000 \\
\hline$\varepsilon_{c 1}=\varepsilon_{c, \text { lim }}$ & 0.00245 & 0.0025 & 0.0026 & 0.0027 & 0.0028 & 0.0028 \\
\hline$\varepsilon_{c u 1}$ & 0.0035 & 0.0032 & 0.003 & 0.0028 & 0.0028 & 0.0028 \\
\hline$k_{e l, c}$ & 0.50 & 0.50 & 0.55 & 0.60 & 0.65 & 0.65 \\
\hline$\lambda_{c, \text { lim }}$ & 0.640 & 0.663 & 0.671 & 0.705 & 0.748 & 0.795 \\
\hline$k_{c}=1-\lambda_{c, \text { lim }}$ & 0.360 & 0.337 & 0.329 & 0.295 & 0.252 & 0.205
\end{tabular}


A short comparison of the different cracking moment calculation methods was carried out. Calculations of the cracking moments $\left(M_{c r}\right)$ were performed according to STR 2.05.05:2005, EC2, ACl 318 and Layer method (LM). When the calculations were performed according to STR, EC2 and $\mathrm{ACl} 318$, in all cases was assumed the transformed cross-section of the reinforced concrete beam.

\section{Technical construction regulation STR 2.05.05:2005}

In the calculations according to STR, it is assumed to use characteristic axial tensile strength of the concrete and plastic moment of resistance of reinforced concrete member effective cross-section. Cracking moment can be calculated by expression:

$$
M_{c r c}=f_{c t k} \cdot W_{p l}
$$
where: $f_{c t k}$ - characteristic axial tensile strength of concrete;

$W_{p l}$ - plastic moment of resistance of $R C$ member effective cross-section.

\section{Design standard EN 1992-1-1}

Design standard EC2 provides elastic stress-strain relation in the calculations of the cracking moment. Here, mean value of axial tensile strength of the concrete and elastic moment of resistance are used to determine $M_{c r c}$ :

$$
M_{c r c}=f_{c t m} \cdot W_{e l}
$$

where: $f_{c t m}$ - mean value of axial tensile strength of concrete; $W_{e l}$ - elastic moment of resistance of $R C$ member effective cross-section.

\section{$\mathrm{ACl} 318$}

Structural building code $\mathrm{ACl} 318$ also uses elastic moment of resistance of $R C$ member effective cross-section. However, modulus of rupture of the concrete is used instead of the axial tensile strength. $M_{c r c}$ can be calculated by expression:

$$
M_{c r c}=f_{r} \cdot W_{e l}
$$

Modulus of rupture of concrete can be expressed:

$$
f_{r}=0.62 \cdot \sqrt{f_{c}^{\prime}}
$$

where: $f_{c}^{\prime}$ - specified compressive strength of concrete.

\section{Layer method}

Layer method (Augonis et al. 2013) was used to calculate the cracking moment evaluating that stress-strain relation of tension concrete is elasto-plastic. The cross-section of the beam was divided into small layers. Strain, stress, and other characteristics were calculated in each layer. Calculations are performed by iterations. LM can be expressed from force and moment equations of equilibrium:

$$
\left\{\begin{array}{l}
\sum_{i=1}^{n} E_{c i} A_{c i} \varepsilon_{c i}+E_{s 1} A_{s 1} \varepsilon_{s 1}+E_{s 2} A_{s 2} \varepsilon_{s 2}=0 \\
\sum_{i=1}^{n} E_{c i} A_{c i} \varepsilon_{c i} z_{c i}+E_{s 1} A_{s 1} \varepsilon_{s 1} z_{s 1}+E_{s 2} A_{s 2} \varepsilon_{s 2} z_{s 2}=M
\end{array}\right.
$$

Calculation of cracking moment according to STR, EC2, ACl 318 and LM 
where: $E_{c i}$ - deformation modulus of concrete of $i$ layer; $A_{c i}$ - area of concrete of $i$ layer, $\varepsilon_{c i}$ - strain of concrete in $i$ layer ("+" in compression zone, "-" in tension zone); $z_{c i}$ - arm of force acting in concrete $i$ layer (distance from the center of the most tension layer to the center of $i$ layer); $E_{s 1}$, $E_{s 2}$ - design value of modulus of elasticity of reinforcing steel; $\varepsilon_{s 1}, \varepsilon_{s 2}$ - strain in tension ("-") and compression ("+) reinforcement; $z_{s 1}, z_{s 2}$-arm of force acting in reinforcement (distance from the center of the most tension layer to the center of reinforcement); $M$ - external bending moment.

Expression (3) is given to calculate coefficient which evaluates elasto-plastic behaviour of compressive concrete. Good correlation was obtained between calculated stress-strain curve and EC2 stress-strain relation. However, to evaluate elasto-plastic behaviour of tension concrete in cracking moment calculations, more accurate expression was suggested. Coefficients $\lambda_{c t}$ can be calculated according to the experssion:

$$
\lambda_{c t}=\frac{1+\left(\frac{\left(1-\lambda_{c t, l i m}\right) \cdot \sigma_{c t, e l}}{f_{c t}-\sigma_{c t, e l}}\right)}{1+\left(\frac{\left(1-\lambda_{c t, l i m}\right) \cdot \varepsilon_{c t, i} \cdot E_{c}}{f_{c t}-\sigma_{c t, e l}}\right)} ;
$$

The parameters of the beams cross-sections are given below. Such parameters were used in order to compare calculated values of $M_{c r c}$ with experimental values. Experimental values of the cracking moments were calculated according to the information (initial cracking load, loading scheme, etc.) given in Kheder et al. (2010) publication. Therefore, some data were used from these scientists' experimental research. Cross-sections of the beams are given in Fig. 3.

\section{Fig. 3}

Parameters of beams cross-sections
Three different types of the beams were used:

- normal strength concrete beams $(275(h) \times 175(b))$;

_ high strength concrete beams $(275(h) \times 175(b))$;

_ composite beams from normal and high strength concrete $\left(90\left(h_{2}\right) / 185\left(h_{1}\right) \times 175(b)\right)$.

Normal strength concrete beams were strengthened by high strength concrete layer in compression zone. Approximately $20 \mathrm{MPa}$ normal strength concrete and about $70 \mathrm{MPa}$ high strength concrete was used in Kheder et al. (2010) experiment.

The beams were double reinforced. Four types of reinforcement were used for beams.

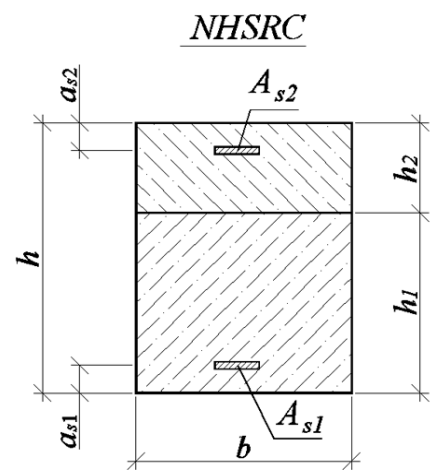

- tension reinforcement: $2 \varnothing 16,3 \varnothing 16\left(a_{s 1}-34 \mathrm{~mm}\right)$, $2 ø 25,3 ø 25\left(a_{s 1}-38.5 \mathrm{~mm}\right),\left(E_{s 1}-205000 \mathrm{MPa}\right)$,

- compression reinforcement: $2 ø 6$ (not given in publication, so assumed that $a_{s 2}-34$ and 38.5 $\mathrm{mm}),\left(E_{\mathrm{s} 2}-210000 \mathrm{MPa}\right)$.

Cylindrical compressive strength and modulus of elasticity of tested beams were used from Kheder et al. (2010) experiment. Tensile strength of the concrete was calculated according to EC2 expressions and it is presented in Table 3. 


\begin{tabular}{c|c|c|c}
\hline \multirow{2}{*}{ Specimen No. } & $f_{c m}(\mathrm{MPa})$ & $f_{c t m}(\mathrm{MPa})$ & $E_{c}(\mathrm{MPa})$ \\
\cline { 2 - 4 } & $N S C / H S C$ & $N S C / H S C$ & $N S C / H S C$ \\
\hline$N S R C / 402$ & $23.6 /-$ & $1.873 /-$ & $24880 /-$ \\
\hline$N S R C / 603$ & $23 /-$ & $1.825 /-$ & $22540 /-$ \\
\hline$N S R C / 982$ & $21 /-$ & $1.659 /-$ & $21530 /-$ \\
\hline$N S R C / 1473$ & $22 /-$ & $1.743 /-$ & $22000 /-$ \\
\hline$H S R C / 402$ & $-/ 65.4$ & $-/ 4.283$ & $-/ 38000$ \\
\hline$H S R C / 603$ & $-/ 71.7$ & $-/ 4.453$ & $-/ 39800$ \\
\hline$H S R C / 982$ & $-/ 74.9$ & $-/ 4.534$ & $-/ 40660$ \\
\hline$H S R C / 1473$ & $-/ 68.8$ & $-/ 4.376$ & $-/ 39000$ \\
\hline$N H S R C / 402$ & $22 / 71.4$ & $1.743 / 4.445$ & $23950 / 41870$ \\
\hline$N H S R C / 603$ & $22 / 71.1$ & $1.743 / 4.437$ & $23700 / 41520$ \\
\hline$N H S R C / 982$ & $21.2 / 68.3$ & $1.676 / 4.363$ & $22460 / 39850$ \\
\hline$N H S R C / 1473$ & $22.3 / 73.7$ & $1.767 / 4.504$ & $24210 / 42530$ \\
\hline
\end{tabular}

Table 3

Properties of tested concrete (Kheder et al. 2010) where: $x x x x / y: x x x x$ - strength of concrete ( $N$ - normal, $H$ - high, $N H$ - composite beam from normal and high strength of concrete); $R$ - reinforced; $y$ - area of tension reinforcement $\left(\mathrm{mm}^{2}\right)$; $E_{c}$ - modulus of elasticity of concrete.

Analysis of the cracking moment calculations was performed according to STR, EC2, ACl 318 and LM. All results were compared with the experimental research results (Kheder et al. 2010). Due to this reason, the mean values of concrete properties were used in the calculation methods given in STR, EC2 and ACl 318. When the calculations were performed according to the available regulations or other standards, it can be observed from the results presented in Table 4 and Fig. 4 that for all types of the beams, the closest to experimental results cracking moments were obtained according to STR and $\mathrm{ACl} 318$. According to EC2 standard, larger errors were obtained. Calculated results for all types of the beams are smaller than experimental values.

\begin{tabular}{|c|c|c|c|c|c|c|}
\hline \multirow[b]{2}{*}{$\begin{array}{c}\text { Specimen } \\
\text { No. }\end{array}$} & \multicolumn{6}{|c|}{ Cracking moment $(\mathrm{kNm})$} \\
\hline & $\begin{array}{c}\text { Experimental } \\
\text { (Kheder et al. } \\
\text { 2010) }\end{array}$ & $\begin{array}{l}\text { Calculated } \\
\text { (STR) }\end{array}$ & $\begin{array}{l}\text { Calculated } \\
\text { (EC2) }\end{array}$ & $\begin{array}{l}\text { Calculated } \\
\text { (ACl 318) }\end{array}$ & $\begin{array}{c}\text { Calculated } \\
(\mathrm{LM}(1), \\
\left.\lambda_{c t, l i m}=\lambda_{c, \text { lim }}\right)\end{array}$ & $\begin{array}{c}\text { Calculated } \\
(\text { LM }(2), \\
\left.\lambda_{c t, \text { lim }} \neq \lambda_{\text {clim }}\right)\end{array}$ \\
\hline NSRC/402 & 10.00 & $8.35(0.84)$ & $4.77(0.48)$ & $7.68(0.77)$ & $7.92(0.79)$ & $10.00(1.00)$ \\
\hline NSRC/603 & 10.46 & $8.83(0.84)$ & $5.05(0.48)$ & $8.23(0.79)$ & $8.88(0.85)$ & $10.46(1.00)$ \\
\hline NSRC/982 & 11.40 & 8.90( & $5.08(0.45)$ & 76) & $9.67(0.85)$ & $11.40(1.00)$ \\
\hline NSRC/1473 & 12.80 & $10.46(0.82)$ & $5.98(0.47)$ & $9.97(0.78)$ & $11.90(0.93)$ & $12.80(1.00)$ \\
\hline HSRC/402 & 18.86 & $18.10(0.96)$ & $10.34(0.55)$ & $12.11(0.64)$ & $13.64(0.72)$ & $18.86(1.00)$ \\
\hline HSRC/603 & 20.26 & $19.45(0.96)$ & $11.11(0.55)$ & $13.10(0.65)$ & $14.68(0.72)$ & $20.26(1.00)$ \\
\hline HSRC/982 & 21.20 & $20.80(0.98)$ & $11.88(0.56)$ & $14.06(0.66)$ & $15.88(0.75)$ & $21.20(1.00)$ \\
\hline$H S R C / 1473$ & 22.60 & $21.82(0.97)$ & $12.47(0.55)$ & $14.65(0.65)$ & $17.45(0.77)$ & $22.60(1.00)$ \\
\hline NHSRC/402 & 11.86 & $8.73(0.74)$ & $4.99(0.42)$ & $8.33(0.70)$ & $8.34(0.70)$ & $10.31(0.87)$ \\
\hline NHSRC/603 & 12.33 & $9.33(0.76)$ & $5.33(0.43)$ & $8.90(0.72)$ & $9.35(0.76)$ & $10.82(0.88)$ \\
\hline NHSRC/982 & 26 & $10.01(0.75)$ & $5.72(0.43)$ & 9.74( & 10.7 & $12.60(0.95)$ \\
\hline$N H S R C / 1473$ & 13.73 & $11.57(0.84)$ & $6.61(0.48)$ & $10.95(0.80)$ & $12.95(0.94)$ & $13.94(1.02)$ \\
\hline
\end{tabular}

\section{Results}

\section{Table 4}

Summary of experimental and calculated results (mean values of concrete properties were used in all calculations) 
Fig. 4

Comparison of cracking moments

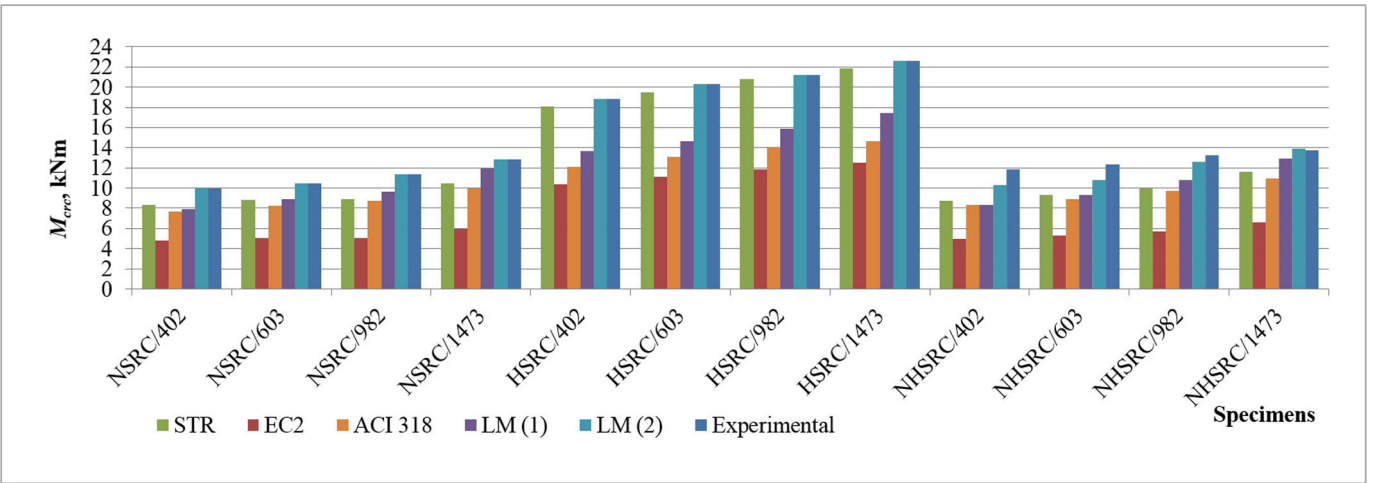

Two cases of the calculations were performed using layer method. In the first case, calculations were performed assuming that the values of the coefficient $\lambda_{c t \text { lim }}$ are equal to $\lambda_{c, \text { lim }}$ (this coefficient was obtained in Section 2, see Table 1 and Table 2, the interpolated values of $\lambda_{c^{\prime} \text { lim }}$ were used depending on $f_{c m}$ ). In the second case, $\lambda_{c t, \text { lim }}$ was expressed from the experimental research results.

CASE 1. The results of the calculations are given in Table 4. The assumptions were made that coefficient $\lambda_{c t, l i m}$ is equal to $\lambda_{c, l i m}, k_{e l, t}$ and $k_{e l, c}$ are equal to 0.4 for NSC and 0.6 for HSC. The values of the calculated cracking moments were obtained smaller than experimental: NSRC (7 - 21\%), HSRC (23-28\%), NHSRC (6-30\%). The largest errors were obtained for HSRC and NHSRC beams.

CASE 2. In this case, new approximate values of coefficient $\lambda_{c t, \text { lim }}$ were expressed from experimental data (NSRC and HSRC beams) for normal strength concrete $\left(f_{c m} \sim 21-23.6 \mathrm{MPa}-\lambda_{c t, \text { lim }}\right.$ vary from 0.281 to 0.385$)$ and for high strength concrete $\left(f_{c m} \sim 65.4-74.9 \mathrm{MPa}-\lambda_{c t}\right.$ lim vary from 0.351 to 0.457). Assumption was made that coefficients $k_{e l, t}$ and $k_{e l, c}$ are equal to 0.4 for normal strength concrete and 0.6 for high strength concrete. $\lambda_{c \text { clim }}$ was used the same as in the case 1. It was assumed that for NSRC and HSRC beams $M_{c r c}$ (calculated) is equal to $M_{c r c}$ (experimental). Expressed coefficients were used to calculate the cracking moments of composite beams. Calculated values of $M_{c r c}$ of NHSRC beams were obtained close to the experimentally determined values. The difference between calculated and experimental values of NHSRC beams varies from 2 to $13 \%$. In the calculations of the flexural members cracking moment, it is very important to know the real limit elastic strain of the tensile concrete and the limit strain of tensile concrete at the peak stress, however design standards provide these approximate values only for compressive concrete. Due to these reasons, coefficients $k_{e l, t}$ and $\lambda_{c t, l i m}$ can be corrected after more analysis.

According to the performed calculations, it can be seen that until the cracking moment, compression zone of the concrete beam behaves elastically $\left(\lambda_{c}=1\right)$. However, the behaviour of tension concrete is quite mysterious, and it is difficult to estimate its real behaviour, therefore it should be noted that suggested coefficients are approximate.

\section{Conclusions}

1 Stress-strain curve calculated according to the expression (3) using $k_{\text {el,c }}$ and $\lambda_{\text {clim }}$ coefficients has a good correlation with stress-strain relation given in design standard EC2. However, for cracking moment calculation more accurate expression (11) was suggested.

2 The values of the cracking moments which were calculated according to STR and ACl 318 are closer to the experimental values as compared to the calculations according to EC2.

$3 \lambda_{c t, l i m}$ coefficients, expressed from the experimentally determined cracking moments of NSC and HSC beams are approximate and can be corrected after more experimental analysis. It is very important to know the real limit elastic strain of the tensile concrete and the limit strain at the peak tensile stress, which are not defined by design standards for the tensile concrete. 
It is observed that partial use of high strength concrete in compression zone of the composite beams can increase the cracking moment as compared to the normal strength concrete beams.

Some data of experimental research were used from Kheder et al., 2010 publication.

$\mathrm{ACl}$ Committee 318. 2005. Building code requirements for structural concrete and commentary $(\mathrm{ACl}$ 318M-05). 436.

Augonis A., Zadlauskas S. 2013. Tampriai plastinių deformaciju itaka gelžbetoninių stačiakampio skerspjūvio elementų pleišejimo momentui ir deformacijoms. [The elastoplastic concrete strain influence on the cracking moment and deformation of rectangular reinforced concrete elements]. Mechanika, 19(1), 5-11. http://dx.doi.org/10.5755/ j01.mech.19.1.3619

EN 1992-1-1:2004. Eurocode 2: Design of concrete structures - Part 1-1: General rules and rules for buildings. 225 .

Iravani S., MacGregor J. G. 1994. High performance concrete under high sustained compressive stresses. Structural engineering report No. 200. Department of Civil Engineering, University of Alberta.

Kheder G. F., Al Kafaji J. M., Dhiab R. M. 2010. Flexural strength and cracking behavior of hybrid strength concrete beams. Materials and Structures, 43(8), 1097-1111. doi:10.1617/s11527-009-9569-9

Kumar M., Ma Z., Matovu M. Mechanical Properties of High-Strength Concrete. Available at: http:// www.acsu.buffalo.edu/ mkumar2/Wikiquake/ Docs/ReportHSC.pdf (accessed 15 March 2014).

Lapko A., Sadowska-Buraczewska B., Tomaszewicz A. 2005. Experimental and numerical analysis of flexural composite beams with partial use of high strength/high performance concrete. Journal of Civil Engineering and Management, 11 (2), 115-120. http:// dx.doi.org/10.1080/13923730.2005.9636340

Mosley W.H., Bungey J.H., Hulse R. 2007. Reinforced concrete design to Eurocode 2. 6th ed. Basingstoke, Palgrave Macmillan.

Sadowska-Buraczewska B., Lapko A. 2007. The concept of strengthening of compressive zone in RC beams using HPC-HSC. In: Proceedings of 9th International Conference: Modern building materials, structures and techniques, Vilnus, Lithuana, 752-757.

Shi C., Mo Y. L., Dhonde H. B. 2008. High performance concrete. In: Shi C., Mo Y. L. Engineering materials for technological needs. High-performance construction materials: Science and applications. Singapore, World Scientific Publishing Co. Pte. Ltd, 91-153.

STR 2.05.05:2005. Design of Concrete and Reinforced Concrete Structures. 123 p. (in Lithuanian).

Wight J.K., MacGregor J. G. 2008. Reinforced concrete. Mechanics \& design. 5th ed. Prentice Hall, New Jersey.

Židonis I. Strength calculation method for cross-section of reinforced concrete flexural member using curvilinear concrete stress diagram of EC-2. In: Proceedings of the 11 th International Conference on Modern Building Materials, Structures and Techniques (MBMST 2013), Vilnius, Lithuania. Procedia Engineering 57, 1309-1318. http://dx.doi.org/10.1016/j.proeng.2013.04.165
TADAS ZINGAILA

\section{$\mathrm{PhD}$ student}

Kaunas University of Technology, Faculty of Civil Engineering and Architecture

\section{Main research area}

Strength, Stability and Serviceability of Reinforced Concrete Structures

\section{Address}

Studentu st. 48, LT-51367, Kaunas, Lithuania

Tel. +370 37300473

E-mail: tadaszingaila@gmail.com

\section{MINDAUGAS AUGONIS}

Associated professor

Kaunas University of Technology, Faculty of Civil Engineering and Architecture, Department of Building Structures

Main research area

Durability of Engineering Structures, Strength and Stability of Reinforced Concrete Structures

\section{Address}

Studentu st. 48, LT-51367, Kaunas, Lithuania.

Tel. +370 37300473

E-mail: mindaugas.augonis@ktu.lt

\section{About the authors}

